\title{
Contribution of Imaging to the Diagnosis of Non-Traumatic Tendinopathies of the Thoracic Limb in a Resource-Constrained Country
}

\author{
Sonia B. M. G. Adjadohoun1, Sessi M. H. G. Kiki², Maurice M. W. D. Akanni' ${ }^{2}$ Houlda Tossa ${ }^{3}$, \\ Boris Vidégla1, Dossou-Yovo Hilaire ${ }^{3}$, Kofi-Mensa S. Savi de Tovè ${ }^{2}$, Patricia Yèkpè Ahouansou ${ }^{1}$, \\ Zavier C. Zomalheto ${ }^{3}$, Olivier Biaou' ${ }^{1}$, Vicentia Boco ${ }^{1}$ \\ ${ }^{1}$ Department of Medical Imaging, Faculty of Health Sciences, University of Abomey-Calavi, Cotonou, Benin \\ ${ }^{2}$ Department of Regional and Teaching Hospital of Borgou/Medical Imaging, Faculty of Medicine, University of Parakou, Parakou, \\ Benin \\ ${ }^{3}$ Department of Rheumatology, Faculty of Health Sciences, University of Abomey-Calavi, Cotonou, Benin \\ Email: mahussi222@yahoo.fr
}

How to cite this paper: Adjadohoun, S.B. M.G., Kiki, S.M.H.G., Akanni, M.M.W.D., Tossa, H., Vidégla, B., Hilaire, D.-Y., de Tove, K.-M.S.S., Ahouansou, P.Y., Zomalheto, Z.C., Biaou, O. and Boco, V. (2021) Contribution of Imaging to the Diagnosis of Non-Traumatic Tendinopathies of the Thoracic Limb in a Resource-Constrained Country. Open Journal of Radiology, 11, 204-217. https://doi.org/10.4236/ojrad.2021.114018

Received: September 16, 2021

Accepted: December 18, 2021

Published: December 21, 202

Copyright $\odot 2021$ by author(s) and Scientific Research Publishing Inc. This work is licensed under the Creative Commons Attribution International License (CC BY 4.0).

http://creativecommons.org/licenses/by/4.0/ (c) (i) Open Access

\begin{abstract}
Introduction: Tendinopathy of the thoracic limb (TMT) is frequent, and is responsible for an important socio-professional handicap. Medical imaging, in particular, ultrasound has a major role in contributing to the diagnosis. As the use of ultrasound is recent in osteoarticular pathology, especially in Africa, we proposed to determine the contribution of imaging in the diagnosis of tendinopathy of the thoracic limbs in a country with limited resources. $\mathrm{Pa}$ tients and Method: A descriptive and analytical cross-sectional study of patients with tendinopathy of the thoracic limb who consulted the rheumatology department of the CNHU-HKM of Cotonou from August 6, 2019 to October 6,2019 . We evaluated the concordance of thoracic limb tendinopathy between imaging (radiography and ultrasound) and the clinic on the one hand and then between radiography and ultrasound on the other hand. The analysis of the collected data was carried out with the Epi-info software version 7.2.1.0. Then the concordance was evaluated by the kappa coefficient. Results: Fiftytwo (52) patients with 104 joints were evaluated. The average age was $54.92 \pm$ 3.40 years. Clinically, rotator cuff tendinopathy was the most frequent abarticular pathology (45.19\%). The clinical-ultrasound agreement was strong $(\mathrm{k}$ $=0.7527)$ for the shoulders, very strong $(\mathrm{k}=0.9360)$ for the elbows and moderate for the wrists $(\mathrm{k}=0.6695)$. The clinical-radiographic agreement was weak $(\mathrm{k}=0.2316)$ at the shoulder level and very weak $(\mathrm{k}=0.2087)$ at the elbow level. The radio-ultrasound agreement was very low in the shoulders $(\mathrm{k}=0.1522)$, elbows $(k=0.1859)$ and wrists $(k=0.0001)$. Conclusion: The contribution of imaging in the diagnosis of TMT remains certain even in a country with lim-
\end{abstract}


ited resources like ours. Ultrasound is a reliable examination for the diagnosis of non-traumatic tendinopathy of the thoracic limb with a good clinical-ultrasound concordance and a weak radio-clinical and radio-ultrasound concordance.

\section{Keywords}

Tendinopathy, Thoracic Limb, Radio-Clinical Concordance,

Clinical-Ultrasound Concordance, Benin

\section{Introduction}

Tendinopathy represents a frequent reason for consultation, accounting for 19\% of musculoskeletal disorders and more than $30 \%$ of consultations in general and sports medicine [1] [2]. Tendinopathy of the thoracic limb (TMT) is the most common occupational pathology in many countries of the world. It is multifactorial pathology that causes a significant socio-professional handicap [3]. The most frequently encountered TMT are, in order of frequency: rotator cuff tendinopathy (shoulder), epicondylitis and epitrochleitis (elbow), De Quervain's tenosynovitis (wrist), and jerky finger (hands). Standard X-ray and ultrasound are the most accessible imaging techniques for the exploration of TMT in our resource-limited countries. Ultrasound has both diagnostic and therapeutic value in tendon pathology [4]. The use of ultrasound is recent in osteoarticular pathology in Africa. Most of the studies conducted on the use of ultrasound in the diagnosis of tendinopathy of the thoracic limb are of interest to the West, and do not take into account African realities. The aim of the present work is to determine the contribution of imaging in thoracic limb tendinopathy in Benin, a country with limited resources.

\section{Patients and Methods}

This was a descriptive and analytical cross-sectional study with prospective data collection over a period of two (2) months from August 2019 to October 2019. An exhaustive enrolment of all patients with thoracic limb tendinopathy was seen in the rheumatology department of the CNHU-HKM during the study period. The patients included in the study met the following criteria:

- A diagnosis of thoracic limb tendinopathy made by a rheumatologist on the basis of clinical arguments;

- Have had an X-ray and an ultrasound of the clinical lesion site;

- Have given informed consent.

A total of 104 joints were studied for the 52 included patients, as only one joint site was examined in a single patient (either shoulders, elbows, or wrists).

Socio-demographic parameters, clinical and paraclinical data (radiography and ultrasound) were studied and then the radio-clinical concordance was evaluated. 
These data were collected on a survey form after a structured individual interview with each patient, followed by the rheumatological examination. Each patient received radiographs of the pathological joint and then a comparative and bilateral ultrasound of the joint site. The ultrasound scans were subsidized by the hospital. Only one joint site was examined comparatively in a single patient (either shoulders, elbows, or wrists). In addition, several tendon abnormalities could be found in the same subject.

Data analysis was performed with Epi-info software version 7.2.1.0. Graphs and frequency tables were made with Excel 2010. Statistical significance was established by a p-value less than or equal to $5 \%$, with a $95 \%$ confidence interval. Cohen's Kappa (k) nonparametric test was used to estimate the rate of agreement or concordance between clinical and para-clinical findings (radiography and ultrasound). The Landis and Koch classification was used to qualitatively assess the agreement rate [5]. Observations were considered to be in agreement when the Kappa coefficient was statistically different from 0 . Agreement was either very poor $(\mathrm{k}=0-0.20)$, poor $(\mathrm{k}=0.21-0.40)$, moderate $(\mathrm{k}=0.41-0.60)$, strong $(\mathrm{k}=$ $0.61-0.80)$ or very strong $(\mathrm{k}=0.81-1)[5]$.

\section{Results}

\subsection{General Characteristics of the Population}

A total of 104 joints were studied (because only one joint site was examined in a single patient, either the shoulders, elbows, or wrists) for the 52 included patients.

The mean age of the patients was $54.92 \pm 3.40$ years with extremes of 21 and 83 years.

There was a predominance of women (40 patients or $76.92 \%)$ with a sex ratio of 0.33 .

\subsection{Clinical Data}

Table 1 summarizes the physical examination data of the patients.

In the shoulder, the Jobe's maneuver was the most frequent tendon test for tendinopathy and the Hakwins sign was the most frequent test for subacromial impingement (37.50\%).

Elbow injuries were revealed by pain on pressure of the lateral or medial side, which was the most frequent palpatory sign in $13(12.50 \%)$ cases and the Middle finger test was the most frequent test in $8(7.69 \%)$ cases.

As for the wrist, the extension of the wrist was the most frequent painful counter movement $10(09.61 \%)$ and the Finkelstein test was the most frequent tendon test $12(11.53 \%)$ cases.

Table 2 shows the distribution of patients according to the clinical diagnosis. Rotator cuff tendinopathy was the most frequent abarticular pathology 47 (45.19\%) cases, followed by De Quervain's tenosynovitis 12 (11.54\%) cases and lateral epicondylitis $6(5.77 \%)$ cases. 
Table 1. Distribution of patients according to the results of the physical examination of shoulders, elbows and wrists, CNHU/HKM rheumatology department, N = 104 .

\begin{tabular}{|c|c|c|c|c|c|c|}
\hline \multirow{2}{*}{ Physical examination time } & \multicolumn{2}{|c|}{ Shoulders } & \multicolumn{2}{|c|}{ Elbows } & \multicolumn{2}{|c|}{ Wrists } \\
\hline & $\mathrm{N}$ & $\%$ & $\mathbf{N}$ & $\%$ & $\mathbf{N}$ & $\%$ \\
\hline \multicolumn{7}{|l|}{ Inspection } \\
\hline Swelling & 1 & 0.96 & 0 & 0 & 12 & 11.54 \\
\hline Bone relief abnormality & 2 & 1.92 & - & - & - & - \\
\hline Amyotrophy of the supraspinous fossa & 2 & 1.92 & - & - & - & - \\
\hline \multicolumn{7}{|l|}{ Palpation } \\
\hline Pain on passive stretching & 10 & 9.62 & 3 & 2.84 & 5 & 4.80 \\
\hline Pain when stretching against resistance & 8 & 7.69 & 6 & 5.77 & 8 & 7.69 \\
\hline Pain on local palpation & 36 & 34.62 & - & - & - & - \\
\hline Local heat & 1 & 0.96 & 1 & 0.96 & 4 & 3.84 \\
\hline Palpatory pain & - & - & 13 & 12.50 & 22 & 21.15 \\
\hline \multicolumn{7}{|l|}{ Painful counter movements } \\
\hline Flexion & 18 & 17.30 & 2 & 1.92 & 9 & 8.65 \\
\hline Extension & 8 & 7.69 & 1 & 0.96 & 10 & 9.61 \\
\hline Abduction & 42 & 40.38 & - & - & 6 & 5.69 \\
\hline Adduction & 7 & 6.73 & - & - & 4 & 3.84 \\
\hline Pronation & - & - & 6 & 5.69 & - & - \\
\hline Supination & - & - & 9 & 8.65 & - & - \\
\hline Internal rotation & 31 & 29.80 & - & - & - & - \\
\hline External rotation & 15 & 14.42 & - & - & - & - \\
\hline \multicolumn{7}{|l|}{ Positive tendon tests } \\
\hline Palm up test & 18 & 17.30 & - & - & - & - \\
\hline Paw test & 24 & 23.07 & - & - & - & - \\
\hline Jobe maneuver & 38 & 36.53 & - & - & - & - \\
\hline Lift off or Gerber maneuver & 33 & 31.73 & - & - & - & - \\
\hline Neer's maneuver & 15 & 14.42 & - & - & - & - \\
\hline Yocum's sign & 36 & 34.61 & - & - & - & - \\
\hline Hawkins sign & 39 & 37.50 & - & - & - & - \\
\hline Positive middle finger & - & - & 8 & 7.69 & & \\
\hline Grip test & - & - & 2 & 1.92 & - & - \\
\hline Finkelstein test & - & - & - & - & 12 & 11.53 \\
\hline Brunelli's test & - & - & - & - & 6 & 5.76 \\
\hline
\end{tabular}

\subsection{Radiographic Data}

Table 3 illustrates the distribution of radiographic abnormalities of the thoracic limbs. 
Table 2. Distribution of patients by clinical diagnosis, CNHU/HKM rheumatology department, $\mathrm{N}=104$.

\begin{tabular}{ccc}
\hline \multicolumn{1}{c}{ Clinical diagnosis retained } & Numbers (N) & Percentages (\%) \\
\hline Rotator cuff tendinopathy & 47 & 45.19 \\
Lateral epicondylitis & 6 & 5.77 \\
Medial epicondylitis & 2 & 1.92 \\
De Quervain's tenosynovitis & 12 & 11.54 \\
No diagnosis/normal clinical examination & 37 & 35.58 \\
Total & 104 & 100.00 \\
\hline
\end{tabular}

Table 3. Distribution of thoracic limb abnormalities on radiography, CNHU/HKM rheumatology department, $\mathrm{N}=104$.

\begin{tabular}{|c|c|c|c|c|c|c|}
\hline \multirow{2}{*}{ Radiographic abnormalities } & \multicolumn{2}{|c|}{ Shoulders } & \multicolumn{2}{|c|}{ Elbows } & \multicolumn{2}{|c|}{ Wrists } \\
\hline & $\mathbf{N}$ & $\%$ & $\mathbf{N}$ & $\mathbf{N}$ & $\%$ & $\mathbf{N}$ \\
\hline Anomaly of the supraspinatus & 7 & 6.73 & - & - & - & - \\
\hline Calcifying tendinopathy & 5 & 4.80 & - & - & - & - \\
\hline Calcifying enthesopathy & 2 & 1.92 & - & - & - & - \\
\hline Calcifying tendinopathy of the subscapularis & 2 & 1.92 & - & - & - & - \\
\hline Anomaly of the infraspinous & 6 & 5.76 & - & - & - & - \\
\hline Calcifying enthesopathy & 1 & 0.96 & - & - & - & - \\
\hline Calcifying tendinopathy & 5 & 4.80 & - & - & - & - \\
\hline Calcifying enthesopathy of the deltoid & 3 & 2.88 & - & - & - & - \\
\hline Calcifying enthesopathy of the brachial triceps & - & - & 1 & 0.96 & - & - \\
\hline \multicolumn{7}{|l|}{ Associated lesions } \\
\hline Morphological abnormality of the acromion & 25 & 24.03 & - & - & - & - \\
\hline Omarthrosis & 14 & 13.46 & - & - & - & - \\
\hline Acromioclavicular osteoarthritis & 13 & 12.50 & - & - & - & - \\
\hline Humero-ulnar osteoarthritis & - & - & 1 & 0.96 & - & - \\
\hline
\end{tabular}

At the shoulder level, radiographs were normal in 60 cases or $57.69 \%$.

The supraspinatus was the most affected tendon with 5 cases of calcific tendinopathy (04.80\%) and 2 cases of calcific enthesopathy (1.92\%).

$\mathrm{X}$-rays of the elbow and wrist were normal in all patients with pain and clinical suspicion of tendinopathy.

\subsection{Ultrasound Data}

We recorded 58 (55.76\%) pathological shoulders on ultrasound with 159 tendon abnormalities (Table 4(a)). The supraspinatus was the most affected tendon (64 cases or $61.53 \%$ ) in the shoulder (Figure 1) and calcific tendinopathy was the most common tendon disorder (27 cases or $25.96 \%$ ). 
Table 4. (a) Distribution of abarticular shoulder anomalies on ultrasound, CNHU/HKM rheumatology department, $\mathrm{N}=58$; (b) Distribution of abarticular abnormalities of the elbows on ultrasound, CNHU/HKM rheumatology department, $\mathrm{N}=104$; (c) Distribution of abarticular wrist abnormalities on ultrasound, CNHU/HKM rheumatology department, $\mathrm{N}=104$; (d) Distribution of ultrasound lesions associated with abarticular anomalies of the thoracic limbs, CNHU/HKM rheumatology department, $\mathrm{N}=104$.

(a)

\begin{tabular}{|c|c|c|}
\hline Topography and type of tendon injuries & Numbers (N) & Percentages (\%) \\
\hline Supra-spinous & 64 & 61.53 \\
\hline Tendinopathy & 9 & 8.65 \\
\hline Fissural tendinopathy & 15 & 14.42 \\
\hline Calcific tendinopathy & 27 & 25.96 \\
\hline Enthesopathy & 7 & 6.73 \\
\hline Rupture & 6 & 5.77 \\
\hline Infraspinous & 53 & 50.96 \\
\hline Fissural tendinopathy & 13 & 12.50 \\
\hline Calcific tendinopathy & 22 & 21.15 \\
\hline Enthesopathy & 7 & 6.73 \\
\hline Rupture & 11 & 10.58 \\
\hline Subscapular & 31 & 29.80 \\
\hline Tendinopathy & 1 & 0.96 \\
\hline Fissural tendinopathy & 7 & 6.73 \\
\hline Calcific tendinopathy & 12 & 11.54 \\
\hline Enthesopathy & 3 & 2.88 \\
\hline Rupture & 8 & 7.69 \\
\hline Long biceps & 11 & 10.57 \\
\hline Tendinopathy & 2 & 1.92 \\
\hline Fissure tendinopathy & 3 & 2.88 \\
\hline Rupture & 3 & 2.88 \\
\hline Subluxation & 3 & 2.88 \\
\hline
\end{tabular}

(b)

\begin{tabular}{ccc}
\hline Ultrasound abnormalities & Numbers (N) & Percentages (\%) \\
\hline Lateral epicondylar tendons & 11 & 10.57 \\
Non-calcific tendinopathy & 5 & 4.80 \\
Enthesopathy & 5 & 4.80 \\
Fissural tendinopathy & 1 & 0.96 \\
\hline Medial epicondylar tendons & 7 & 6.73 \\
Calcific tendinopathy & 3 & 2.88 \\
Non-calcific tendinopathy & 2 & 1.92 \\
Enthesopathy & 2 & 1.92 \\
\hline
\end{tabular}




\section{Continued}

\begin{tabular}{ccc}
\hline Triceps tendon & $\mathbf{3}$ & $\mathbf{2 . 8 8}$ \\
Fissural tendinopathy & 1 & 0.96 \\
Calcific tendinopathy & 1 & 0.96 \\
Enthesopathy & 1 & 0.96 \\
\hline
\end{tabular}

(c)

\begin{tabular}{lcc}
\hline Ultrasound abnormalities & Numbers (N) Percentages (\%) \\
\hline 1st compartment & 20 & 19.23 \\
Tenosynovitis of the abductor pollicis longus & 6 & 5.77 \\
Enthesopathy of the abductor pollicis longus & 4 & 3.84 \\
Tenosynovitis of the extensor pollicis brevis & 4 & 3.84 \\
Tendinopathy of the extensor digitorum brevis & 3 & 2.88 \\
Tendinopathy of the abductor pollicis longus & 3 & 2.88 \\
\hline 2nd compartment & 6 & 5.77 \\
Tenosynovitis of the extensor carpi radialis longus & 2 & 1.92 \\
Tenosynovitis of the extensor carpi radialis brevis & 2 & 1.92 \\
Tendinopathy of the extensor carpi radialis brevis & 1 & 0.96 \\
Tendinopathy of the extensor carpi radialis longus & 1 & 0.96 \\
\hline 3rd compartment & 1 & 0.96 \\
Tenosynovitis of the extensor pollicis longus & 1 & 0.96 \\
\hline 4th compartment & 1 & 0.96 \\
Tenosynovitis of the extensor digitorum and & 1 & 0.96 \\
extensor indicis & 1 & 0.96 \\
\hline 5th compartment & 1 & 0.96 \\
Tendinopathy of the extensor digiti minimi & 1 & 0.96 \\
Tenosynovitis of the extensor digiti minimi & 1 & \\
\hline Eth compartment & 1 & 0.96 \\
\hline Extensor carpi ulnaris tenosynovitis & 1 & \\
\hline
\end{tabular}

(d)

\begin{tabular}{lcccccc}
\hline \multirow{2}{*}{ Ultrasound lesions associated } & \multicolumn{2}{c}{ Shoulders } & \multicolumn{2}{c}{ Elbows } & \multicolumn{2}{c}{ Wrists } \\
\cline { 2 - 7 } & N & $\%$ & N & $\%$ & N & $\%$ \\
\hline Degenerative bone lesions & 29 & 27.88 & 1 & 0.96 & 1 & 0.96 \\
Intra-articular fluid effusion & 25 & 24.03 & 1 & 0.96 & 1 & 0.96 \\
Pathology of the SASD & 24 & 23.08 & - & - & - & - \\
Acromioclavicular osteoarthritis & 23 & 22.11 & - & - & - & - \\
Fatty involution & 14 & 13.46 & - & - & - & - \\
Synovitis & - & - & - & - & 13 & 12.50 \\
Amyotrophy & 6 & 5.76 & - & - & - & - \\
Presence of impingement & 6 & 5.76 & - & - & - & - \\
Bone erosion & - & - & - & - & 2 & 1.92 \\
Radio carpal osteoarthritis & - & - & - & - & 2 & 1.92 \\
\hline
\end{tabular}

${ }^{\star}$ SASD = subacromial-subdeltoid bursa. 
Nine (9 or 8.65\%) of the elbows were pathological on ultrasound with 21 tendon abnormalities (Table 4(b)). The lateral epicondylar tendons (Figure 2) were the most affected (11 cases 10.57\%) and non-calcific tendinopathies were the most common tendon condition of the elbow. Doppler activity was positive in two patients.

Tendinopathies found on wrist ultrasound were 31 (Table 4(c)) for $08(07.69 \%)$ pathological wrists. De Quervain's tenosynovitis (abnormality of the 1st compartment of the wrist) was the most frequent abnormality with 20 cases (19.23\%) and a Doppler hyperemia in one patient (Figure 3).

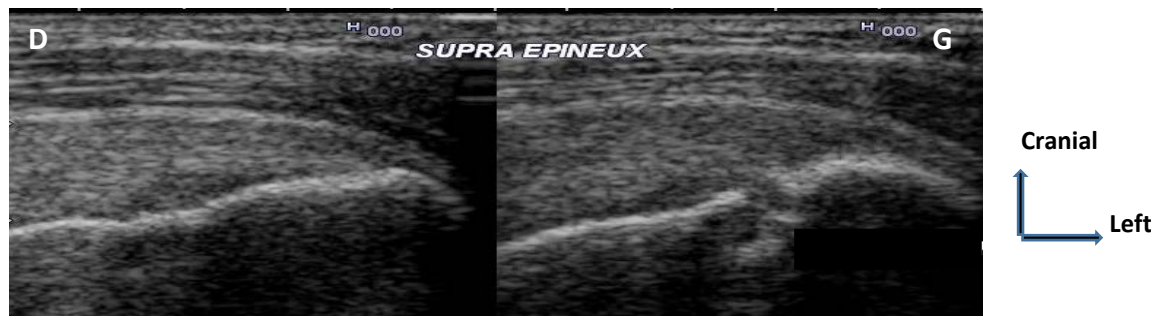

Figure 1. Oblique coronal section of the right and left supraspinatus tendons showing erosion of the trochlea with a left non-calcific tendinopathy, in a patient of the series.

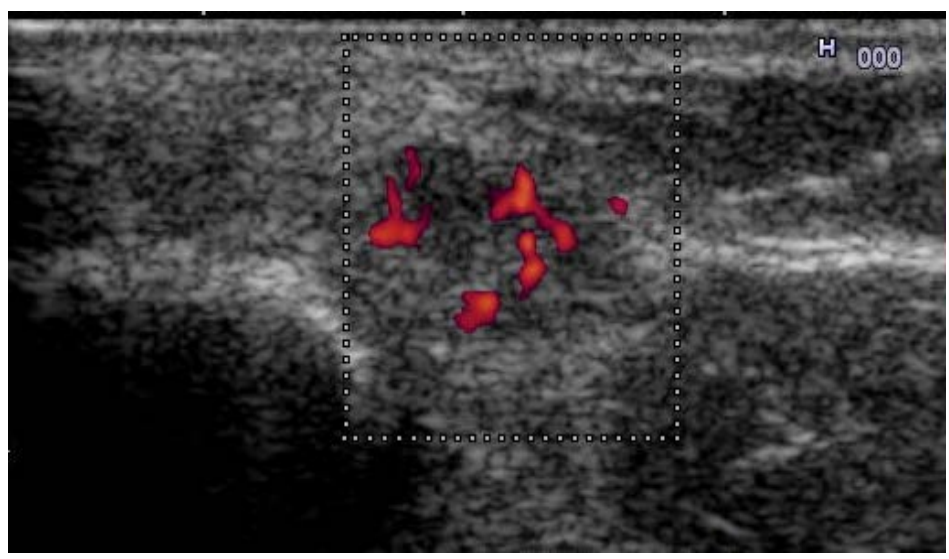

Cranial

$\uparrow$ Left

Figure 2. Longitudinal section of the common tendon of the lateral epicondyles illustrating a right lateral epicondylitis, active in a patient of the series.

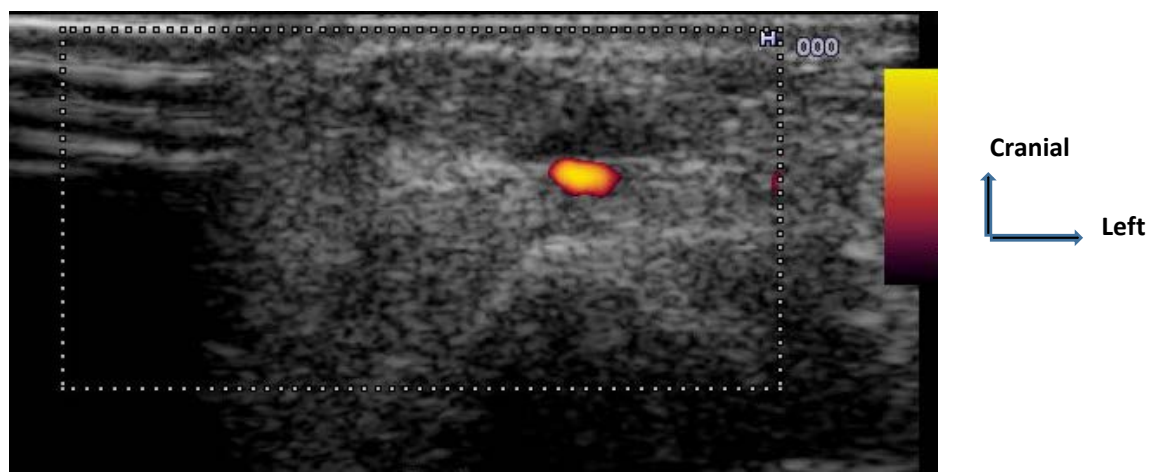

Figure 3. Axial section of the 1st dorsal compartment of the left wrist showing De Quervain's tenosynovitis in a patient of the serie. 
Apart from tendon abnormalities, ultrasound allowed us to find some associated lesions summarized in Table 4(d). The most frequent were, in order of frequency, degenerative bone lesions followed by intra-articular fluid effusion, particularly in the shoulders.

\subsection{Analytical Data}

The radio-clinical concordance study at the level of the shoulders, elbows and wrists is summarized in Table 5.

The study of the radio-clinical concordance at the level of the shoulders, elbows and wrists revealed that: the concordance between the clinical results and those of the ultrasound was strong $(\mathrm{k}=0.7527)$ at the level of the shoulders, very strong $(\mathrm{k}=0.9360)$ at the level of the elbows and moderate at the level of the wrists $(k=0.6695)$. The agreement between clinical and radiographic findings was low $(k=0.2316)$ at the shoulder level and very low $(k=0.2087)$ at the elbow and the wrists $(\mathrm{k}=0.0001)$.

Table 6 shows the concordance between radiography and ultrasound in the diagnosis of tendinopathy in the shoulders, elbows and wrists, which is very low.

Table 5. Radio-clinical concordance of tendinopathy in the shoulders, elbows and wrists; CNHU/HKM rheumatology department, $\mathrm{N}=104$.

\begin{tabular}{|c|c|c|c|c|c|}
\hline \multirow[b]{2}{*}{ Radiology } & \multicolumn{2}{|c|}{ Clinical } & \multirow[b]{2}{*}{ Total } & \multirow[b]{2}{*}{$\mathbf{k}$} & \multirow{2}{*}{$\begin{array}{c}\text { Interpretation } \\
\text { of the } \\
\text { concordance }\end{array}$} \\
\hline & $\begin{array}{c}\text { Tendinopathy } \\
(+)\end{array}$ & $\begin{array}{c}\text { Tendinopathy } \\
(-)\end{array}$ & & & \\
\hline \multicolumn{6}{|l|}{ Shoulder } \\
\hline \multicolumn{6}{|l|}{ Radiography } \\
\hline Tendinopathy $(+)$ & 11 & 1 & 12 & \multirow{2}{*}{0.2316} & \multirow{3}{*}{ Low } \\
\hline Tendinopathy (-) & 36 & 56 & 92 & & \\
\hline Total & 47 & 57 & 104 & & \\
\hline \multicolumn{6}{|l|}{ Ultrasound } \\
\hline Tendinopathy $(+)$ & 46 & 12 & 58 & \multirow{2}{*}{0.7527} & \multirow{3}{*}{ High } \\
\hline Tendinopathy (-) & 1 & 45 & 46 & & \\
\hline Total & 47 & 57 & 104 & & \\
\hline \multicolumn{6}{|l|}{ Elbow } \\
\hline \multicolumn{6}{|l|}{ Radiography } \\
\hline Tendinopathy $(+)$ & 1 & 0 & 1 & 0.2087 & \multirow{3}{*}{ Very low } \\
\hline Tendinopathy (-) & 7 & 96 & 103 & & \\
\hline Total & 8 & 96 & 104 & & \\
\hline \multicolumn{6}{|l|}{ Ultrasound } \\
\hline Tendinopathy $(+)$ & 8 & 1 & 9 & 0.9360 & \multirow{3}{*}{ Very high } \\
\hline Tendinopathy (-) & 0 & 95 & 95 & & \\
\hline Total & 8 & 96 & 104 & & \\
\hline
\end{tabular}




\section{Continued}

\begin{tabular}{lccccc}
\hline Wrist & & & & \\
\hline Radiography & & & & & \\
$\quad$ Tendinopathy (+) & 0 & 92 & 104 & & Very low \\
$\quad$ Tendinopathy (-) & 12 & 92 & 104 & & \\
Total & 12 & & & & \\
Ultrasound & 7 & 1 & 8 & 0.6695 & \\
$\quad$ Tendinopathy $(+)$ & 5 & 91 & 96 & & High \\
$\quad$ Tendinopathy $(-)$ & 5 & 92 & 104 & & \\
Total & 12 & &
\end{tabular}

Table 6. Concordance between radiography and ultrasound in the diagnosis of tendinopathy, CNHU/HKM Rheumatology Department, $\mathrm{N}=104$.

\begin{tabular}{|c|c|c|c|c|c|}
\hline \multirow[b]{2}{*}{ Ultrasound } & \multicolumn{2}{|c|}{ Radiography } & \multirow[b]{2}{*}{ Total } & \multirow[b]{2}{*}{$\mathbf{k}$} & \multirow{2}{*}{$\begin{array}{c}\text { Interpretation } \\
\text { of the } \\
\text { concordance }\end{array}$} \\
\hline & $\begin{array}{c}\text { Tendinopathy } \\
(+)\end{array}$ & $\begin{array}{c}\text { Tendinopathy } \\
(-)\end{array}$ & & & \\
\hline \multicolumn{6}{|l|}{ Shoulder } \\
\hline Tendinopathy (+) & 11 & 47 & 58 & & \\
\hline Tendinopathy (-) & 1 & 45 & 46 & 0.1522 & Very low \\
\hline Total & 12 & 92 & 104 & & \\
\hline \multicolumn{6}{|l|}{ Elbow } \\
\hline Tendinopathy (+) & 1 & 8 & 9 & & \\
\hline Tendinopathy (-) & 0 & 95 & 95 & 0.1859 & Very low \\
\hline Total & 1 & 103 & 104 & & \\
\hline \multicolumn{6}{|l|}{ Wrist } \\
\hline Tendinopathy (+) & 0 & 8 & 8 & & \\
\hline Tendinopathy (-) & 0 & 96 & 96 & 0.0001 & Very low \\
\hline Total & 0 & 104 & 104 & & \\
\hline
\end{tabular}

\section{Discussion}

Tendinopathies are encountered above all in a context of hyper solicitation. The quality of the diagnosis depends above all on the accuracy of the clinical examination. The questioning and the physical examination with the realization of tendon tests will make it possible to reach a clinical lesion diagnosis.

Among the tendon tests performed on the shoulders in our patients, the Jobe maneuver was the most frequent (36.53\%), with supra-spinous tendinopathies in the rotator cuff lesions but also in the tendinopathies of the thoracic limb. Wafa et al. [3] made the same observation with a frequency of $59.2 \%$. This can be explained by the fact that during subacromial impingement, the supraspinatus is in permanent contact with the coracoacromial ligament, which predisposes it to wear 
out more rapidly than the other tendons of the rotator cuff.

In patients with elbow involvement, we found much more pain in the lateral aspect as shown by the Middle finger test which was the most frequent tendon test $(7.69 \%)$. These results confirm the data of the literature which had shown that tendinopathies of the lateral aspect of the elbow were the most frequent TMT of the elbow [3] [6].

In the wrists, the Finkelstein test was predominant (11.53\%), testifying to the frequency of De Quervain's tenosynovitis in the wrists, thus corroborating the data in the literature [3].

In the majority of cases, after the clinical examination, it is necessary to resort to imaging to refine the diagnosis of the lesion and decide on a therapeutic strategy. Standard radiographic images are the first step in the imaging assessment, regardless of the size and apparent nature of the lesions. These images are systematically prescribed, although their contribution remains limited in tendon pathology. They are used to look for indirect signs of injury, in particular small bone changes in relation to a tendon insertion and calcifications. In the present study, we recorded 60 (57.69\%) normal shoulder radiographs, 10 (9.62\%) normal elbow radiographs and 13 (12.5\%) normal wrist radiographs. Tendinopathy of the supraspinatus in its calcifying form was visualized in 5 cases, i.e., $04.80 \%$, followed by 2 cases of calcifying enthesopathy, i.e., 1.92\%. We found one (1) case of humeroulnar osteoarthritis, one (1) case of triceps enthesopathy, one (1) radio-carpal osteoarthritis and one (1) inter-phalangeal osteoarthritis and rhizarthrosis. These observations confirm that radiography is the gold standard for the diagnosis of calcific tendinopathies [7] and the detection of chronic bone damage, but its contribution remains insignificant in non-calcific tendinopathies, hence the interest of osteoarticular ultrasound.

Technological advances and the development of consensus have considerably improved the reproducibility of ultrasound, as long as the quality of the machine and the experience of the examiner are taken into account [7]. Nowadays, ultrasound is becoming increasingly important in musculoskeletal pathology in general and in the diagnosis of tendinopathies in particular. Even if it is an examination that depends on the dexterity of the sonographer, and that the reproducibility is low, this study allowed us to describe the contribution of ultrasound in the diagnosis of tendinopathies of the thoracic limb and to evaluate the concordance between the clinical data and the imaging data (ultrasound/radiography) on the one hand, and the concordance between radiography and ultrasound on the other hand. From our results, it appears that ultrasound detects 4 times more than radiography tendinopathies of the shoulder, 8 times more those of the elbow and 7 times more those of the wrist. This could be explained by the fact that ultrasound analysis of tendon injuries is particularly easy for superficial tendons [8].

Indeed, several studies have confirmed the good sensitivity and specificity of ultrasound to detect rotator cuff damage [8] [9] [10]. These studies also noted 
that there was no significant difference between the performance of ultrasound and Magnetic Resonance Imaging (MRI) in the detection of rotator cuff injuries [8] [9] [10]. Ultrasound thus appears to be a reliable tool of choice for the evaluation of rotator cuff tendon injuries. It is more sensitive than MRI and radiography for the identification of calcifications [8]. At the elbows, the lateral epichondylar tendons were the most affected (10.57\%). This is consistent with the literature [6]. Non-calcific tendinopathy was the most common type of abnormality and sometimes associated with intra-tendinous Doppler activity. These results reinforce the usefulness of ultrasound for the accurate assessment of the affected tendons and the type of tendon abnormality [8]. The tendons of the 1st dorsal compartment of the wrist were the most affected (19.23\%) and De Quervain's tenosynovitis was the most frequent tendinopathy. These data are consistent with the literature [3].

The agreement between clinical and ultrasound findings was hight $(\mathrm{k}=0.7527)$ in the shoulders and wrists $(\mathrm{k}=0.6695)$ but she was very higth $(\mathrm{k}=0.9360)$ in the elbows. The agreement between clinical and radiographic findings was low $(\mathrm{k}$ $=0.2316)$ at the shoulder, and very low $(\mathrm{k}=0.2087)$ at the elbow and the wrists $(\mathrm{k}=0.001)$. This could be explained by the fact that the diagnosis of tendinopathies is primarily clinical and ultrasound would be used to confirm the clinical diagnosis, but especially to assess the injury [8] [11]. Ultrasound allows a better exploration of the large joints than the smaller ones (wrists and hands) which require the dexterity of the operator but also adapted probes like the golf probe which was not available in our context.

In countries with limited resources such as ours, a good clinical examination thus allows us to make an almost certain diagnosis of tendon pathology. However, imaging remains useful because, apart from tendinopathy, ultrasound can reveal other abnormalities such as bursitis and synovitis, and joint effusions, which are a source of pain and which go unnoticed in the clinic as well as in the radiograph. Finally, ultrasound also has a therapeutic role in guiding infiltrations or the evacuation of effusions.

The concordance between radiographic and ultrasonographic findings was very low in the shoulders $(\mathrm{k}=0.1522)$, elbows $(\mathrm{k}=0.1859)$ and wrist $(\mathrm{k}=0.0001)$. This low radio-ultrasound concordance can be explained by the fact that radiography only detects calcifications and chronic bone abnormalities such as osteophytes, enthesophytes and erosions in the majority of cases and does a very poor job of analysing the tendon. In addition to these lesions, ultrasound detects and analyses the tendon better. It can easily identify tendon ruptures, whether they are partial or complete with a loss of continuity of the tendon and retraction. Calcification or, more rarely, an intra tendinous tophus can also be seen. At the level of the tendon insertion (enthesis), ultrasound may reveal calcifications, called enthesophytes [8].

\section{Conclusion}

The contribution of imaging in the diagnosis of TMT remains definite even in a 
country with limited resources such as ours. Ultrasound is a reliable examination for the diagnosis of non-traumatic tendinopathy of the thoracic limb with a good clinical-ultrasound concordance and a poor radio-clinical and radio-ultrasound concordance. Therefore, it is necessary to make it more available and more accessible in our current practice, for better diagnostic accuracy and adequate management of the patients. However, its reliability depends on the quality of the machine and the experience of the examiner.

\section{Limitation of the Study}

The main limitation of this work is the small sample size and the fact that the study is monocentric. These biases do not allow us to extrapolate our results to the rest of the population. This does not detract from the validity of our results. An extension of the study with a larger number of patients should be considered to determine more precisely the diagnostic values of the different clinical tests in relation to ultrasound and, if possible, to MRI.

\section{Acknowledgements}

The authors acknowledge all the patients followed for rheumatoid arthritis who agreed to collaborate in this study.

\section{Author Contributions}

All authors contributed to the design of the paper, the drafting of the article, its critical revision and the final approval of the version to be published.

\section{Conflicts of Interest}

The authors declare no conflicts of interest regarding the publication of this paper.

\section{References}

[1] Brulhart, L. (2015) Contribution of Ultrasound in Tendinopathies. Swiss Medical Review, 11, 612-615.

[2] Haddad, A. (2012) Tendinopathies of the Elbow. Journal of Rheumatism Monographs, 79, 64-71.

[3] Kaux, J.-F., Forthomme, B., Goff, C.L., Crielaard, J.-M. and Croisier, J.-L. (2011) Current Opinions on Tendinopathy. Journal of Sports Science and Medicine, 10, 238-253.

[4] Landis, J.R. and Koch, G.G. (1977) The Measurement of Observer Agreement for Categorical Data. Biometrics, 33, 159-174. https://doi.org/10.2307/2529310

[5] Lecoq, B., Fournier, L., Carteni, M., Morin, F. and Marcelli, C. (2006) Ultrasound in Rheumatology. Le Rhumatologue, 71, 14-19.

[6] Lellouche H. (2012) Dorsal Tendinopathies of the Wrist. Revue du Rhumatisme Monographies, 79, 122-125. https://doi.org/10.1016/j.monrhu.2012.01.003

[7] Riley, G. (2008) Tendinopathy-From Basic Science to Treatment. Nature Clinical Practice Rheumatology, 4, 82-89. https://doi.org/10.1038/ncprheum0700 
[8] Rutten, M.J.C.M., Spaargaren, G.-J., van Loon, T., de Waal Malefijt, M.C., Kiemeney, L.A.L.M. and Jager, G.J. (2010) Detection of Rotator Cuff Tears: The Value of MRI following Ultrasound. European Radiology, 20, 450-457. https://doi.org/10.1007/s00330-009-1561-9

[9] Vuillemin, V., Guérini, H., Thévenin, F. and Morvan, G. (2015) The Radiography/Ultrasound Pair in Calcifiant Tendinopathies of the Shoulder. Le Rhumatologue, 10-12.

[10] Wafa, E., Aida, B., Saloua, I., Nesrine, B., Khaoula, L., Nihel, K., et al. (2016) Occupational Upper Extremity Tendinopathies in a Center: A 10-Year Study. About 65 Cases. Tunisian Journal of Occupational and Environmental Pathology, 4, 33-40.

[11] Wannes, W., Jemni, S., Benzarti, H., Frioui, S., Osman, W., Frigui, S., et al. (2015) Rotator Cuff Pathology: Confrontation of Clinical Diagnosis and Ultrasonographic Findings. Journal de Réadaptation Médicale. Pratique et Formation en Médecine Physique et de Réadaptation, 35, 117-123. https://doi.org/10.1016/j.jrm.2015.04.005 